\title{
Characterization of Sb-doped $\mathrm{Bi}_{2} \mathrm{UO}_{6}$ Solid Solutions by X-ray Diffraction and X-ray Absorption Spectroscopy
}

\author{
N. L. Misra, ${ }^{*}{ }^{\dagger}$ A. K. Yadav, ${ }^{2}$ Sangita Dhara, ${ }^{* 1}$ S. K. Mishra, ${ }^{3}$ Rohan PhataK, $* 1$ \\ A. K. Poswal, ${ }^{* 2}$ S. N. Jha, ${ }^{* 2}$ A. K. Sinha, ${ }^{* 4}$ and D. BhatTacharyya $* 2 \dagger$ \\ *1 Fuel Chemistry Division, Bhabha Atomic Research Centre, Mumbai-400094, India \\ *2 Applied Spectroscopy Division, Bhabha Atomic Research Centre, Mumbai-400094, India \\ *3 Solid State Physics Division, Bhabha Atomic Research Centre, Mumbai-400094, India \\ *4 Indus Synchrotron Utilization Division, Raja Ramanna Centre for Advanced Technology, Indore-452013, \\ India
}

\begin{abstract}
The preparation and characterization of $\mathrm{Sb}$-doped $\mathrm{Bi}_{2} \mathrm{UO}_{6}$ solid solutions, in a limited composition range, is reported for the first time. The solid solutions were prepared by solid-state reactions of $\mathrm{Bi}_{2} \mathrm{O}_{3}, \mathrm{Sb}_{2} \mathrm{O}_{3}$ and $\mathrm{U}_{3} \mathrm{O}_{8}$ in the required stoichiometry. The reaction products were characterized by X-ray diffraction (XRD) and X-ray absorption spectroscopy (XAS) measurements at the $\mathrm{Bi}$ and $\mathrm{U} \mathrm{L}_{3}$ edges. The XRD patterns indicate the precipitation of additional phases in the samples when $\mathrm{Sb}$ doping exceeds 4 at\%. The chemical shifts of the Bi absorption edges in the samples, determined from the XANES spectra, show a systematic variation only up to 4 at $\%$ of Sb doping and support the results of XRD measurements. These observations are further supported by the local structure parameters obtained by analysis of the EXAFS spectra. The local structure of $\mathrm{U}$ is found to remain unchanged upon $\mathrm{Sb}$ doping indicating that $\mathrm{Sb}^{+3}$ ions replace $\mathrm{Bi}^{+3}$ during the doping of $\mathrm{Bi}_{2} \mathrm{UO}_{6}$ by $\mathrm{Sb}$.
\end{abstract}

(Received February 10, 2013; Accepted March 13, 2013; Published May 10, 2013)

\section{Introduction}

Uranates of different elements are reported in the literature since they may form by interactions of uranium nuclear fuel with fission products, cladding as well as coolants in the operating and transient conditions of a reactor. ${ }^{1}$ Due to large difference in the densities of the uranates and uranium/uranium oxide/mixed oxide fuel, the formation of these compounds play an important role in safety issues arising from any rupture of the cladding materials due to swelling of the fuel. ${ }^{2}$ In addition, the uranates have applications as magnetic materials, catalysts etc. ${ }^{3-5}$ Bismuth uranates are a special class of compounds having relevance in several areas e.g. nuclear technology and the demethylation of toluene, ${ }^{6,7}$ as well as having good oxide ion-transport properties. India is proposing to produce nuclear power using compact high-temperature reactors with $\mathrm{Pb}-\mathrm{Bi}$ alloys as the coolant and uranium as nuclear fuel. In the case of the fuel-coolant interaction under transient conditions, Bi and $\mathrm{Pb}$ uranates are likely to form in such nuclear reactors. ${ }^{8}$ Antimony uranates are also being applied in the field of catalysis for variety of industrial processes. Though, various studies on $\mathrm{Bi}_{2} \mathrm{UO}_{6}{ }^{9,10}$ have been reported in the literature, the similar antimony uranate has not been reported so far, despite both $\mathrm{Sb}$ and $\mathrm{Bi}$ being from the same group of the periodic table. A few studies have been reported in the literature on the preparation of uranium-doped $\mathrm{Bi}_{4} \mathrm{~V}_{2} \mathrm{O}_{11}$ and $\mathrm{Bi}_{2} \mathrm{WO}_{6}$, it was observed ${ }^{11}$ that $\mathrm{U}^{+6}$

† To whom correspondence should be addressed.

E-mail: nlmisra@barc.gov.in, nlmisra@yahoo.com (N. L. M.); dibyendu@barc.gov.in (D. B.) takes the position of $\mathrm{V}^{+5}$ in $\mathrm{Bi}_{4} \mathrm{~V}_{2} \mathrm{O}_{11}$, whereas $\mathrm{U}$ replaces $\mathrm{W}$ in solid solutions of $\mathrm{Bi}_{2} \mathrm{WO}_{6}$ and $\mathrm{Bi}_{2} \mathrm{UO}_{6}{ }^{12}$ In similar work on $\mathrm{Zr}$ doping of $\mathrm{Bi}_{2} \mathrm{UO}_{6}$, it has been observed that $\mathrm{Zr}$ atoms go to $\mathrm{U}$ sites. ${ }^{13}$ Since $\mathrm{Bi}^{+3}$ and $\mathrm{Sb}^{+3}$ have similar ionic radii, it should be possible to dope $\mathrm{Bi}_{2} \mathrm{UO}_{6}$ with $\mathrm{Sb}^{+3}$. Such solid solutions may show properties different from undoped $\mathrm{Bi}_{2} \mathrm{UO}_{6}$. Keeping the above points in mind, a study to prepare and characterize $\mathrm{Sb}^{+3}$ doped $\mathrm{Bi}_{2} \mathrm{UO}_{6}$ by X-ray diffraction (XRD) and X-ray absorption spectroscopy (XAS): extended X-ray absorption fine structure (EXAFS) and X-ray absorption near edge spectroscopy (XANES) measurements was initiated. The results obtained in this study are reported in the present manuscript.

\section{Experimental}

\section{Preparation of the compounds}

The starting materials, $\mathrm{Bi}_{2} \mathrm{O}_{3}$ and $\mathrm{Sb}_{2} \mathrm{O}_{3}$, used were of $\mathrm{AR}$ grade, whereas $\mathrm{U}_{3} \mathrm{O}_{8}$ used was of nuclear grade. The compound $\mathrm{Bi}_{2} \mathrm{UO}_{6}$ was prepared by mixing $\mathrm{Bi}_{2} \mathrm{O}_{3}$ and $\mathrm{U}_{3} \mathrm{O}_{8}$ in stoichiometric ratios, and heating at $800^{\circ} \mathrm{C}$ for about $100 \mathrm{~h}$ continuously in a platinum boat inside a furnace. Sb-doped $\mathrm{Bi}_{2} \mathrm{UO}_{6}$ solid solutions were prepared by heating stoichiometric amounts of $\mathrm{Bi}_{2} \mathrm{O}_{3}$, $\mathrm{Sb}_{2} \mathrm{O}_{3}$ and $\mathrm{U}_{3} \mathrm{O}_{8}$ appropriate for the formation of $\mathrm{Bi}_{2-\mathrm{x}} \mathrm{Sb}_{\mathrm{x}} \mathrm{UO}_{6}$ solid solutions having $\mathrm{x}=0.04,0.08,0.12,0.16$ and 0.40 .

\section{XRD measurements}

Powder X-ray diffraction studies on the samples were carried out using a $\mathrm{Cu}$ anode-based powder diffractometer operating in the Bragg-Brentano focusing geometry, and a curved crystal monochromator in the diffraction beam. Structural refinements 
were performed using the Rietveld refinement program, FULLPROF. ${ }^{14}$ In all the refinements, the background was defined by a sixth-order polynomial in $2 \theta$. A Thompson-CoxHastings pseudo-Voigt with an axial divergence asymmetry function was chosen to define the profile shape for the X-ray diffraction peaks. Except for the occupancies of the atoms, all other parameters i.e., scale factor, zero correction, background and half-width parameters along with mixing parameters, lattice parameters, positional coordinates, and thermal parameters, were refined.

For a better purity check, the XRD patterns of some of the reaction products were also measured using the angle dispersive $\mathrm{X}$-ray diffraction beam line (BL-12) ${ }^{15}$ at Indus-2 synchrotron source at RRCAT, Indore, India. The beam line consists of a $\mathrm{Si}(311)$ based double-crystal monochromator with bendable focusing optics. These measurements were done at $11000 \mathrm{eV}$ using an image-plate area detector (MAR 345). Photon energy calibration for this set of samples was done using powder diffraction of the $\mathrm{LaB}_{6}$ standard (NIST). For the above measurements, a few mg of a powdered sample was pressed in between two sticky layers of cellophane tapes.

\section{XAS measurements}

For XAS measurements, samples of appropriate weight, estimated to obtain a reasonable edge jump, were taken in powder form and mixed thoroughly with cellulose powder to obtain a total weight of about $100 \mathrm{mg}$; homogenous pellets of $15 \mathrm{~mm}$ diameter were prepared using an electrically operated hydraulic press. XAS measurements were carried out at the dispersive EXAFS beam line (BL-8) in the transmission mode at the INDUS-2 Synchrotron Source. ${ }^{16-20}$

The above mentioned beam line uses a Si(111)-based bent crystal as polychromator and a position-sensitive CCD detector; the full XAS spectrum of a sample at any specified absorption edge can be obtained as a single shot within a time frame of $300 \mathrm{~ms}$. For the present measurement on $\mathrm{Bi}_{2} \mathrm{UO}_{6}$ samples, the $\mathrm{Si}(111)$ crystal was set at a proper Bragg angle to obtain a band of energy around $13419 \mathrm{eV}$ for XAS measurements at $\mathrm{Bi} \mathrm{L}_{3}$ edge, and around $17166 \mathrm{eV}$ for XAS measurements at the $\mathrm{U} \mathrm{L}_{3}$ edge. Pellets of standard powders of $\mathrm{Bi}_{2} \mathrm{O}_{3}$ and $\mathrm{PbO}\left(\mathrm{L}_{3}\right.$-edge of $\mathrm{Pb}$ being $13037 \mathrm{eV}$ ) were used for calibration of the CCD channels for measurements at the $\mathrm{Bi}_{3}$ edge, while standard samples of $\mathrm{U}_{3} \mathrm{O}_{8}$ and $\mathrm{Y}_{2} \mathrm{O}_{3}(\mathrm{Y}$ K-edge being at $17050 \mathrm{eV}$ ) were used for measurements at the $\mathrm{U} \mathrm{L}_{3}$ edge.

\section{Results and Discussion}

\section{XRD measurements}

The X-ray powder diffraction measurements for $\mathrm{Bi}_{2} \mathrm{UO}_{6}$ at ambient temperature confirmed that the sample was single-phase. All reflections could be indexed with the cell parameter of the low-temperature phase of $\mathrm{Bi}_{2} \mathrm{UO}_{6}$ with space group $C 2$ reported in the litreture. ${ }^{13}$ The XRD pattern of $\mathrm{Bi}_{2} \mathrm{UO}_{6}$ along with the Rietveld profile is shown in Fig. 1(a). The XRD patterns of reaction products obtained while preparing $\mathrm{Bi}_{2-\mathrm{x}} \mathrm{Sb}_{\mathrm{x}} \mathrm{UO}_{6}$ solid solutions for $\mathrm{x}=0.04,0.08,0.12$ and 0.16 are shown in Fig. 1(b). The appearance of some extra peaks, in addition to that reported for $\mathrm{Bi}_{2} \mathrm{UO}_{6}$, could be seen in the range of $28-30^{\circ}$ in the XRD patterns of the products with $\mathrm{x}$ values of more than 0.4 , possibly due to the formation of an additional phase. The additional new lines start appearing in the XRD patterns of the samples with $\mathrm{Sb}$ doping of $4 \mathrm{at} \%$, and become clearly visible for samples with $\mathrm{Sb}$ doping of more than 6 at\% ( $\mathrm{x} \geq 0.12)$. However, the intensities of these additional peaks were very
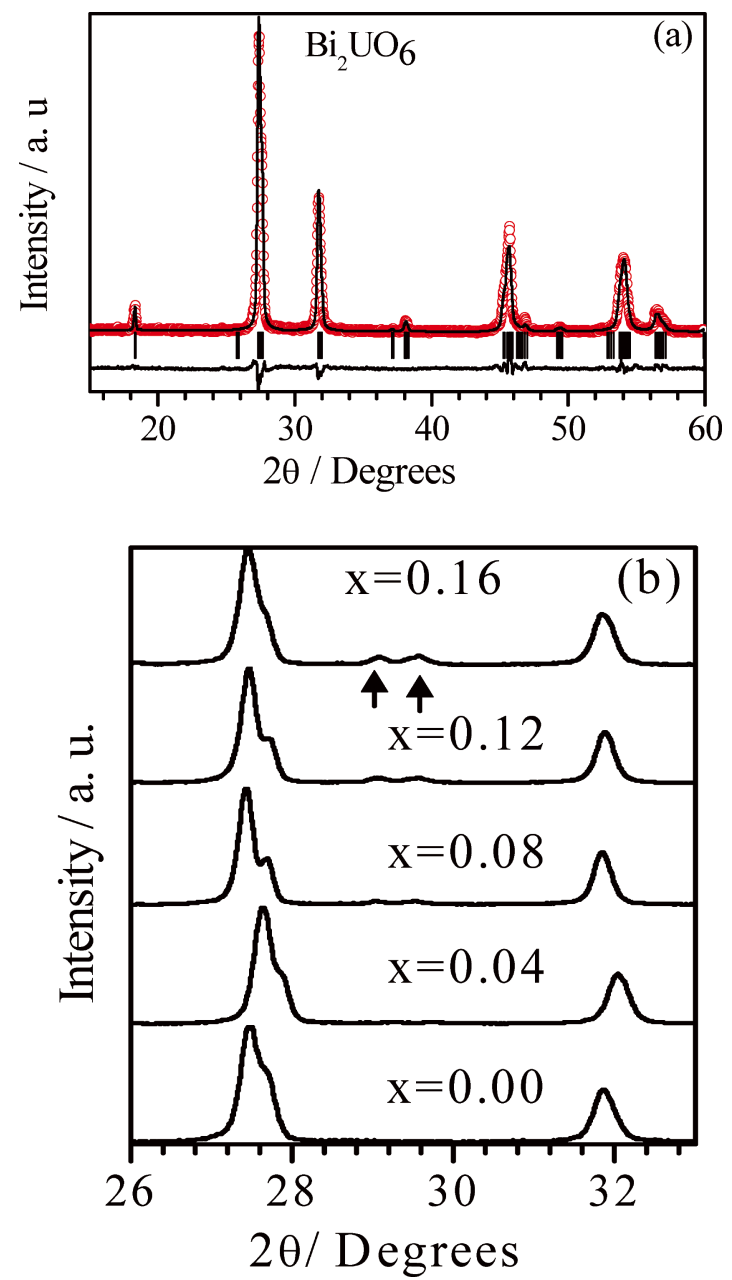

Fig. 1 (a) Rietveld fitting of $\mathrm{XRD}$ pattern of $\mathrm{Bi}_{2} \mathrm{UO}_{6}$ (closed circle, Experimental; continuous line, best-fit theoretical curves obtained after the Rietveld refinement of $\mathrm{Bi}_{2} \mathrm{UO}_{6}$ using monoclinic $C 2$ space group; bottom line: difference profiles.) (b) Evolution of powder XRD patterns of reaction products obtained while preparing $\mathrm{Bi}_{2-\mathrm{x}} \mathrm{Sb}_{\mathrm{x}} \mathrm{UO}_{6}$ samples for different values of $x$ in the $2 \theta$ region of $\left(26-34^{\circ}\right)$.

weak and could be observed only in the expanded scale of the XRD patterns. Several intense XRD lines of this phase could be seen at $\mathrm{x}=0.40$. However, this additional phase could not be identified. Rietveld profile fits were also carried out on the XRD patterns of the above mentioned reaction product, and the variations of the best-fit cell parameters as a function of the value of $x$ are shown in Figs. 2(a) and 2(b). It was observed that the cell parameters $(\mathrm{a}, \mathrm{b}, \mathrm{c}$ values, monoclinic angle $\beta$ and cell volume) generally decrease upon $\mathrm{Sb}$ doping up to 4 at\% (i.e. $\mathrm{x}=0.08$ in $\left.\mathrm{Bi}_{2-\mathrm{x}} \mathrm{Sb}_{\mathrm{x}} \mathrm{UO}_{6}\right)$ in $\mathrm{Bi}_{2} \mathrm{UO}_{6}$, after which the cell parameters are invariant with the composition. These observations were further supported when the XRD patterns of $\mathrm{Bi}_{2-\mathrm{x}} \mathrm{Sb}_{2} \mathrm{UO}_{6} \quad(\mathrm{x}=0.4)$ samples were measured using a synchrotron-radiation source.

\section{Bi-edge EXAFS}

XAS studies on different uranates are reported in the literature for obtaining information about the local uranium environment and its valence state., ${ }^{4,5}$ The XAS studies were performed on Sb-doped $\mathrm{Bi}_{2} \mathrm{UO}_{6}$ for this information. The near-edge or XANES regions of the normalized absorption spectra $(\mu(E)$ vs. $E$ ) measured at the $\mathrm{Bi}_{3}$-edge are shown in Fig. 3(a) for solid 

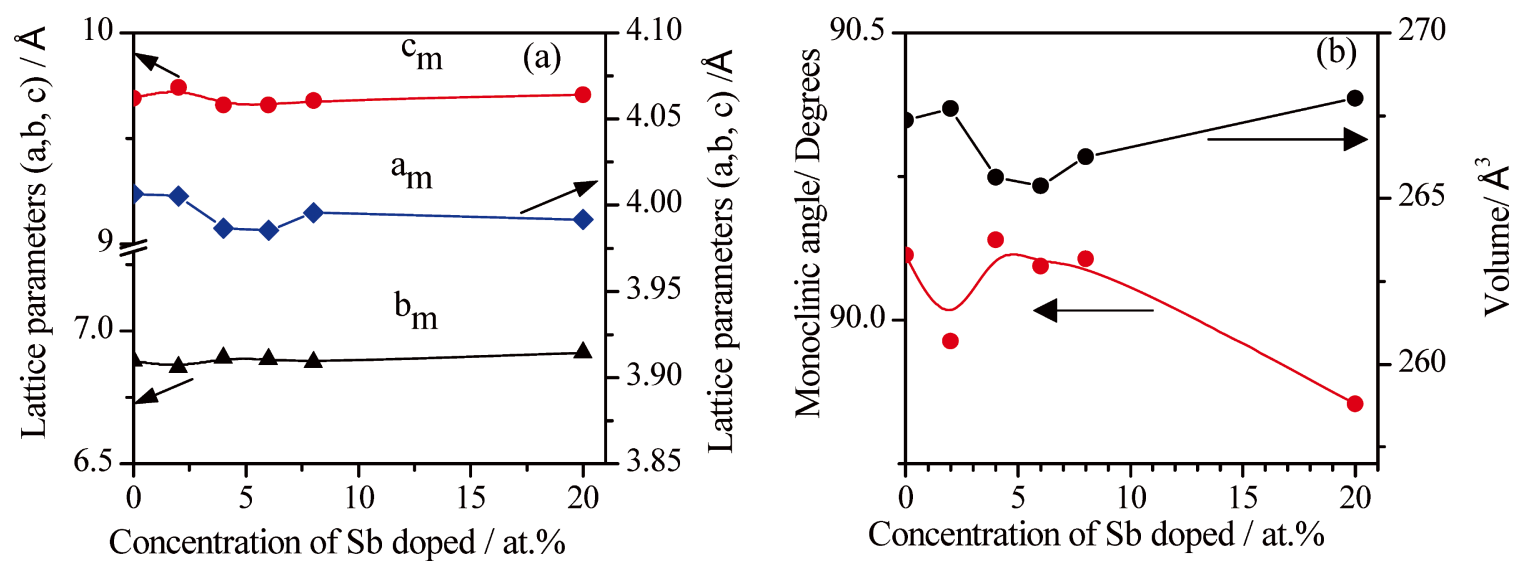

Fig. 2 Variation of the structural parameters (lattice constants and cell volume) for products obtained while preparing $\mathrm{Bi}_{2-\mathrm{x}} \mathrm{Sb}_{\mathrm{x}} \mathrm{UO}_{6}$ samples for different $\mathrm{Sb}$ doping concentrations.
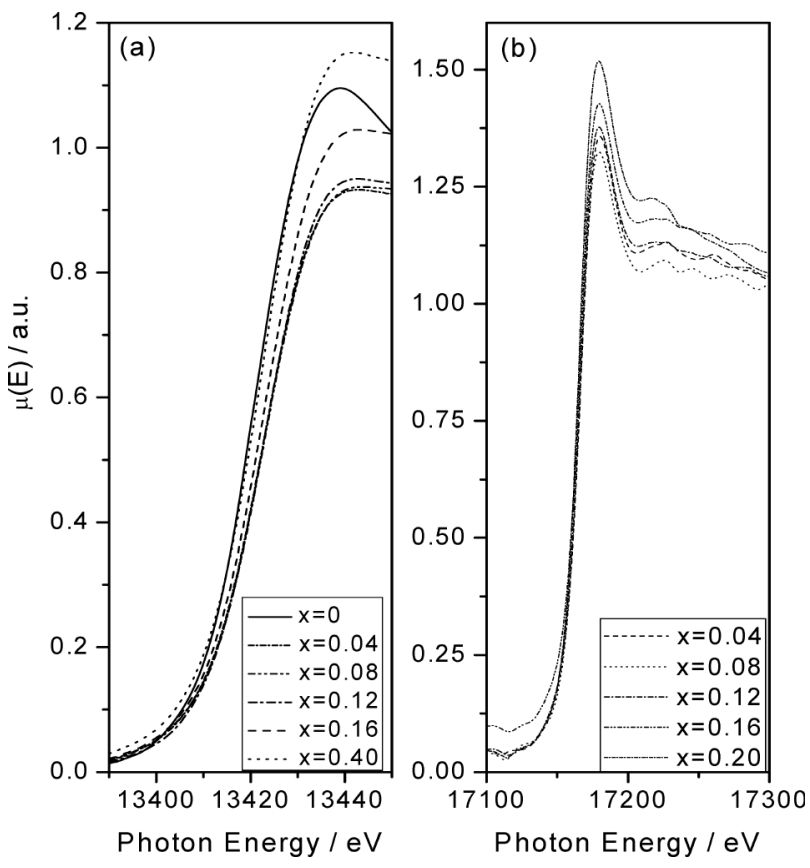

Fig. 3 Normalized X-ray absorption spectra (XANES region) of $\mathrm{Bi}_{2-\mathrm{x}} \mathrm{Sb}_{\mathrm{x}} \mathrm{UO}_{6}$ samples measured at (a) the $\mathrm{Bi}_{3}$ edge and (b) the $\mathrm{U} \mathrm{L}_{3}$ edge.

solutions having different $\mathrm{Sb}$ doping concentrations. It can be seen that there is a considerable shift in the $\mathrm{Bi}$ absorption edge position from sample to sample. The actual edge positions of the samples were obtained by the "half-edge step" method in each case from their respective $\mu(E) v s . E$ spectrum. The edge shift $(\Delta E)$ value i.e., the difference in the edge energy with respect to the edge energy of an undoped $\mathrm{Bi}_{2} \mathrm{UO}_{6}$ sample, are tabulated in Table 1. Since $\mathrm{Bi}$ is in $\mathrm{Bi}^{+3}$ state in all of the samples, the edge shift must be because of a change in the chemical environment surrounding the Bi sites due to Sb doping. Similar shifts in the X-ray absorption edges due to change in the chemical environment of the absorbing species have been observed by several other authors in different systems. ${ }^{21-23}$ Figure 3(a) shows that the edge energy values are shifted towards the higher energy side as the $\mathrm{Sb}$ doping concentration increases up to $4 \%(\mathrm{x}=0.08)$ and beyond that edge shift start decreasing as the doping concentration further increases. This
Table 1 Measured chemical shift and calculated effective charge

\begin{tabular}{lcc}
\hline \multicolumn{1}{c}{ Sample } & Chemical shift, $\Delta E / \mathrm{eV}$ & $\begin{array}{c}\text { Effective charge } \\
q \text { (electrons/atom) }\end{array}$ \\
\hline $\mathrm{Bi}_{2} \mathrm{UO}_{6}$ & 0 & 0.54 \\
$\mathrm{Bi}_{1.96} \mathrm{Sb}_{0.04} \mathrm{UO}_{6}$ & 3.13 & 0.55 \\
$\mathrm{Bi}_{1.92} \mathrm{Sb}_{0.08} \mathrm{UO}_{6}$ & 3.27 & 0.57 \\
$\mathrm{Bi}_{1.88} \mathrm{Sb}_{0.12} \mathrm{UO}_{6}$ & 3.18 & 0.58 \\
$\mathrm{Bi}_{1.84} \mathrm{Sb}_{0.16} \mathrm{UO}_{6}$ & 2.15 & 0.6 \\
\hline
\end{tabular}

shows that the Bi site is replaced by doped $\mathrm{Sb}$ properly up to $4 \%$ $\mathrm{Sb}$ doping only. At higher $\mathrm{Sb}$ doping concentrations, another phase starts precipitating, as also indicated by XRD studies. In the case of $20 \% \mathrm{Sb}$ doping, the edge is almost at the same energy position as observed for undoped $\mathrm{Bi}_{2} \mathrm{UO}_{6}$.

It is reported in the litreture ${ }^{21-25}$ that these effects of change in the chemical environment can be quantitatively presented by the "effective charge" $(q)$. The formation of a chemical bond in a compound involves a redistribution of the valence electrons of the constituent atoms and the effective charge is a hypothetical parameter that gives a measure of the charge residing over the cation when it forms a bond with a ligand. Apart from the valency, it accounts for the electronegativity of the pair of atoms forming the bond, the covalent nature of the bond, the coordination number etc. and thus quantitatively represents the chemical environment around the absorbing metal ions.

Several empirical relations ${ }^{21-25}$ have been proposed in the literature to estimate the effective charge on a metal cation in a compound. According to Suchet's method, ${ }^{26}$ the effective charge on a cationic species involved in the formation of a chemical bond is given by

$$
q=n\left[1-0.01185\left(\frac{Z}{r^{\prime}}+\frac{Z^{\prime}}{r}\right)\right]
$$

where $Z, r$ and $n$ are, respectively, the total number of electrons, the ionic radius and the oxidation number of the cation. The primed symbols refer to the anion in the compounds.

In case of $\mathrm{Bi}_{2} \mathrm{UO}_{6}$, where two cations are involved, the effective charge on $\mathrm{Bi}$ was estimated following the method described in Ref. 25 for $\mathrm{LaMnO}_{3}$. In such calculations, $\mathrm{Bi}_{2} \mathrm{UO}_{6}$ was considered to consist of two separate compounds viz., $\mathrm{Bi}_{2} \mathrm{O}_{3}$ and $\mathrm{UO}_{3}$ with $\mathrm{Bi}$ in the +3 oxidation state and $\mathrm{U}$ in the +6 
oxidation state. The combination of these two compounds will yield the molecular formula $\mathrm{Bi}_{2} \mathrm{UO}_{6}$. For $\mathrm{Bi}_{2} \mathrm{O}_{3}$, we obtained $q_{\mathrm{Bi}}=+0.54$ and $q_{\mathrm{O}}=-0.36$ electrons/atom by using Eq. (1) given above. Similarly, for $\mathrm{UO}_{3}$ we obtained $q_{\mathrm{U}}=+0.66$ and $q_{\mathrm{O}}=-0.22$ electrons/atom. When two individual molecules combine to produce $\mathrm{Bi}_{2} \mathrm{UO}_{6}$, each oxygen atom would have an average charge of -0.29 electrons/atom. The charge on $\mathrm{Bi}$ atoms and $\mathrm{U}$ atoms would still be the same, i.e. +0.54 and +0.66 electrons/atom, thereby ascertaining a total charge neutrality of the $\mathrm{Bi}_{2} \mathrm{UO}_{6}$ molecule.

For calculating the effective charge on $\mathrm{Bi}$ in $\mathrm{Sb}$-doped $\mathrm{Bi}_{2} \mathrm{UO}_{6}$, we first calculated the $q$ values of the $\mathrm{Sb}_{2} \mathrm{O}_{3}$ molecule using Eq. (1), which gave $q_{\mathrm{Sb}}=+1.29$ and $q_{\mathrm{O}}=-0.86$ electrons/atom. To calculate the contribution of oxygen in $2 \% \mathrm{Sb}$ doped $\mathrm{Bi}_{2} \mathrm{UO}_{6}$, we took the weighted average of the $q$ value of oxygen as of $98 \%$ of $\mathrm{Bi}_{2} \mathrm{O}_{3}$ and $2 \% \mathrm{Sb}_{2} \mathrm{O}_{3}$, which is -0.37 electrons/atom. Considering the contribution of $\mathrm{UO}_{3}$, each oxygen atom has an average charge of -0.295 electrons/atom in the $2 \% \mathrm{Sb}$ doped $\mathrm{Bi}_{2} \mathrm{UO}_{6}$ molecule. Since, as discussed later, $\mathrm{Bi}_{2} \mathrm{UO}_{6}$ is a layered compound that consists of a stacking of slabs of edge-sharing $\mathrm{UO}_{8}$ polyhedra sandwiched between double $\mathrm{BiO}$ sheets and the U-polyhedra remains almost unperturbed by $\mathrm{Sb}$ doping, the charge on the $\mathrm{U}$ atoms in $\mathrm{Sb}$-doped $\mathrm{Bi}_{2} \mathrm{UO}_{6}$ should be the same as in the case of undoped $\mathrm{Bi}_{2} \mathrm{UO}_{6}$, which is 0.66 electrons/atom. Hence, to satisfy the total charge neutrality condition, the effective charge, $q$, on the $\mathrm{Bi}$ atom in $2 \% \mathrm{Sb}$ doped $\mathrm{Bi}_{2} \mathrm{UO}_{6}$ should be +0.55 electrons/atom, which is higher than that in case of undoped $\mathrm{Bi}_{2} \mathrm{UO}_{6}$ (+0.54 electrons/atom). The above result is consistent with the fact that $\mathrm{Sb}$, being more electronegative than $\mathrm{Bi}, \mathrm{Sb}$ doping, should increase the effective positive charge at $\mathrm{Bi}$ sites. Using the above procedure, we calculated the effective charge, $q$, on the $\mathrm{Bi}$ atom in all $\mathrm{Sb}$ doped products, as tabulated in Table 1, along with the shift in the edge energy vales $(\Delta E)$.

In order to take care of the oscillations in the EXAFS region of the absorption spectra, $\mu(E)$ has been converted to an absorption function, $\chi(E)$, defined as follows ${ }^{27}$

$$
\chi(E)=\frac{\mu(E)-\mu_{0}(E)}{\Delta \mu_{0}\left(E_{0}\right)}
$$

where, $E_{0}$ is the absorption edge energy, $\mu_{0}\left(E_{0}\right)$ the bare atom background and $\Delta \mu_{0}\left(E_{0}\right)$ the step in the $\mu(E)$ value at the absorption edge. The energy-dependent absorption coefficient, $\chi(E)$, has been converted to the wave-number dependent absorption coefficient, $\chi(k)$ using the relation

$$
K=\sqrt{\frac{2 m\left(E-E_{0}\right)}{\hbar^{2}}}
$$

where $m$ is the electron mass, $\chi(k)$ is weighted by $k^{2}$ to amplify the oscillation at high $k$ and the $\chi(k) k^{2}$ functions are Fourier transformed in $R$ space to generate the $\chi(R) v s . R$ spectra in terms of the real distances from the center of the absorbing atom. The set of EXAFS data analysis available within the IFEFFIT software package have been used for EXAFS data analysis. ${ }^{28}$ This includes background reduction and Fourier transform to derive the $\chi(R) v s$. $R$ spectra from the absorption spectra (using ATHENA software), the generation of theoretical EXAFS spectra starting from an assumed crystallographic structure, and finally fitting of the experimental data with the theoretical spectra using ARTEMIS software.

The structural parameters (atomic coordination and lattice parameters) of $\mathrm{Bi}_{2} \mathrm{UO}_{6}$ used for simulating theoretical EXAFS spectra of the samples were obtained from reported values in the literature. ${ }^{6,9,10,13} \quad \mathrm{Bi}_{2} \mathrm{UO}_{6}$ is reported to display two polymorphs: a monoclinic form at $20^{\circ} \mathrm{C}$ that crystallizes in the $C 2$ space group with $a=6.8782 \AA, b=4.0057 \AA, c=9.6939 \AA, \beta=90.11^{\circ}$, and a trifocal fluorite-like structure stable above $800^{\circ} \mathrm{C}$, with space group $P \overline{3}$ and $a=4.045 \AA, c=9.90 \AA^{6}$. In the present analysis, theoretical EXAFS spectra of the samples were generated assuming the monoclinic form of the crystal in the $C 2$ space group.

$\chi(R)$ vs. $R$ spectra have been generated for all samples from the $\mu(E)$ versus $E$ spectra following the methodology described above; also the best-fit $\chi(R) v s$. $R$ spectra of the samples are shown in Fig. 4(a), along with the experimental data for all samples. The bond distances, co-ordination numbers (including scattering amplitudes) and disorder (Debye-Waller) factors $\left(\sigma^{2}\right)$, which give the mean-square fluctuations in the distances, were used as fitting parameters.

\section{U-edge EXAFS}

The near-edge or XANES regions of the normalized absorption spectra $(\mu(E)$ vs. $E)$ measured at $\mathrm{U} \mathrm{L}_{3}$-edge are shown in Fig. 3(b) for all $\mathrm{Bi}_{2} \mathrm{UO}_{6}$ samples having different $\mathrm{Sb}$ doped concentrations. This indicates that the $\mathrm{U}$ absorption edge is not affected by Sb doping. Figure 4(b) shows the radial distribution functions i.e., $\chi(R)$ vs. $R$ spectra of the samples with different $\mathrm{Sb}$ concentrations as obtained from the EXAFS portion of the absorption spectra, with theoretical fit curves up to $3.5 \AA$. The theoretical EXAFS spectra were generated assuming the structure described above. The bond distances, co-ordination numbers (including scattering amplitudes) and disorder (Debye-Waller) factors $\left(\sigma^{2}\right)$, which give the mean-square fluctuations in the distances, were used as fitting parameters.

$\mathrm{Bi}_{2} \mathrm{UO}_{6}$ is a layered compound that consists of a stacking of slabs of edge-sharing $\mathrm{UO}_{8}$ polyhedra sandwiched between double $\mathrm{BiO}$ sheets. The $\mathrm{BiO}$ sheet resembles a fluorite structure, where $\mathrm{Bi}$ atoms are coordinated by 4 in-plane oxygen $\left(\mathrm{O}_{2}\right.$ type $)$ and three out of plane oxygen $\left(\mathrm{O}_{3}\right.$ type $)$ which connects it to the $\mathrm{UO}_{8}$ polyhedra. In the $\mathrm{UO}_{8}$ polyhedra, each uranium atom is coordinated with 8 oxygen atoms, of which two oxygens $\left(\mathrm{O}_{3}\right.$ type) form collinear uranyl bonds, and the rest of the 6 oxygen atoms $\left(\mathrm{O}_{1}\right.$ type $)$ form a hexagon whose atoms lie a little above and below the plane perpendicular to the uranyl bond. ${ }^{13}$ Since the $\mathrm{BiO}$ sheets are relatively empty compared to the U-O planes, these layers are responsible for ionic conduction in $\mathrm{Bi}_{2} \mathrm{UO}_{6}$ systems. The $\mathrm{Bi}-\mathrm{O}_{2}$ and $\mathrm{Bi}-\mathrm{O}_{3}$ bond lengths and the $\mathrm{U}-\mathrm{O}_{1}$ and $\mathrm{U}-\mathrm{O}_{3}$ bond lengths, as obtained from the present EXAFS analysis, are found to agree well with that reported by Vannier et al. ${ }^{13}$

It should be noted that, Vannier et al., ${ }^{13}$ while refining the neutron diffraction data of $\mathrm{Bi}_{2} \mathrm{UO}_{6}$, have introduced an extra oxygen site in the double $\mathrm{BiO}$ sheet (named as $\mathrm{O}_{2 \mathrm{~b}}$ site), and also another oxygen site $\left(\mathrm{O}_{1 \mathrm{~b}}\right)$ in the equatorial plane of the $\mathrm{U}-\mathrm{O}$ network. The present EXAFS study shows the presence of bond lengths corresponding to the $\mathrm{Bi}-\mathrm{O}_{2 \mathrm{~b}}$ and $\mathrm{U}-\mathrm{O}_{1 \mathrm{~b}}$ bonds in the case of the undoped and $\mathrm{Sb}$-doped $\mathrm{Bi}_{2} \mathrm{UO}_{6}$ samples, which agree well with the values reported by Vannier et al. ${ }^{13}$

The average bond lengths $\left(\mathrm{R}_{\mathrm{AVG}}\right)$, total coordination number $\left(\mathrm{N}_{\text {Tот. }}\right)$ and average Debye-Waller factor $\left(\sigma_{\mathrm{AVG}}{ }^{2}\right)$ for the first two nearest oxygen shells surrounding the $\mathrm{Bi}$ atoms (as obtained from Bi edge EXAFS analysis) and average bond lengths, the total coordination number and the average Debye-Waller factor surrounding the $U$ atoms (as obtained from $U$ edge EXAFS analysis) are plotted in Fig. 5 as a function of $x$. It can be found from this figure that there are significant changes in the bond length, coordination number and $\sigma^{2}$ values up to $\mathrm{x}=0.08$ (4\% $\mathrm{Sb}$ doped samples) with respect to the undoped sample. For 


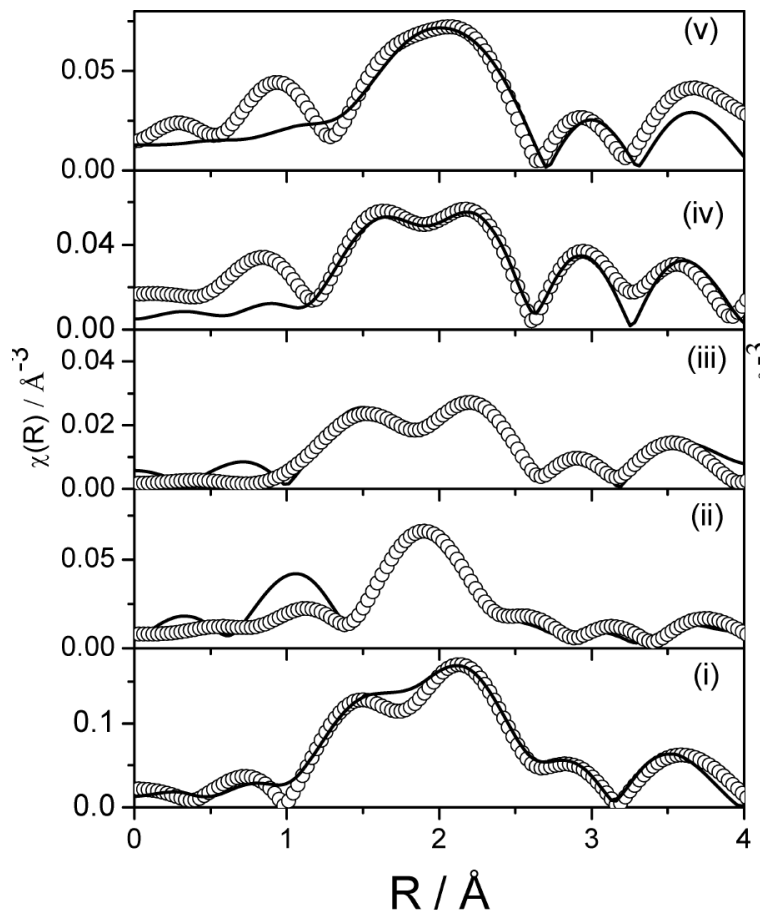

(a)

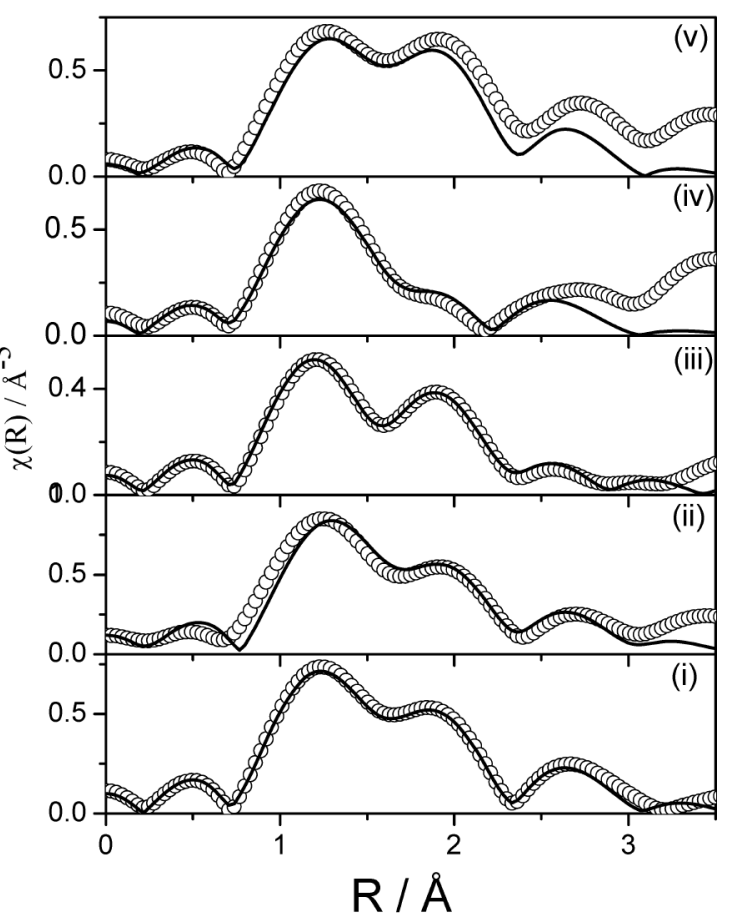

(b)

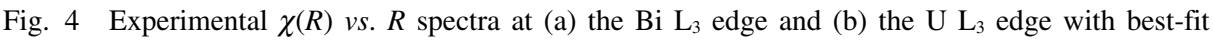
theoretical plots for products obtained while preparing $\mathrm{Bi}_{2-\mathrm{x}} \mathrm{Sb}_{\mathrm{x}} \mathrm{UO}_{6}$ samples: (i) $\mathrm{x}=0.04$, (ii) $\mathrm{x}=0.08$, (iii) $\mathrm{x}=0.12$, (iv) $\mathrm{x}=0.16$, (v) $\mathrm{x}=0.4$. The solid line represents fitting data, and scatter points are measured data.

samples with a higher concentration of Sb doping, the above values, however, approach towards that of the undoped samples. Based on this observation it can be concluded that up to $4 \%$ concentration, $\mathrm{Sb}$ can efficiently substitute $\mathrm{Bi}$, above which $\mathrm{Sb}$ precipitation takes place. This supports the XRD and XANES results discussed above. From Fig. 5 it can also be seen that the bond length, coordination number and Debye-Waller factors in the $\mathrm{U}$ surrounding do not change much, indicating that $\mathrm{Sb}$ atoms do not go to the $\mathrm{U}$ sites. This may be due to the fact that uranium in $\mathrm{Bi}_{2} \mathrm{UO}_{6}$ is in the $\mathrm{U}^{+6}$ oxidation state, but $\mathrm{Sb}$ is more stable in the $\mathrm{Sb}^{+3}$ oxidation state.

\section{Conclusions}

The XRD and EXAFS studies confirm that $\mathrm{Bi}_{2-\mathrm{x}} \mathrm{Sb}_{\mathrm{x}} \mathrm{UO}_{6}$ solid solutions are formed properly with $\mathrm{x} \leq 0.08$ i.e. up to 4 at $\%$ of $\mathrm{Sb}$. The cell parameters ( $a, b, c$ values and cell volume) of the samples generally decrease with an increase in $\mathrm{Sb}$ atom, \% in solid solutions up to 4 at\% of $\mathrm{Sb}$. However, when $\mathrm{Sb}$ doping is increased beyond $6 \%$, a separate phase precipitates. The chemical shift of the $\mathrm{Bi}_{3}$ edge in XANES measurements of the samples also supports this observation. Though the oxidation state of $\mathrm{Bi}$ is +3 in all of these solid solutions, there is a chemical shift in the $\mathrm{Bi}_{3}$ edge, as observed in XANES measurements on the samples. This is due to the variation in the effective atomic charge at the Bi sites, due to Sb doping in the lattice, arising as a result of differences in the electronegativity of the $\mathrm{Sb}^{+3}$ and $\mathrm{Bi}^{+3}$ ions. The chemical shift increases with the $\mathrm{Sb}$ doping concentration up to $4 \%$ at $\%$, beyond which it decreases; at higher $\mathrm{Sb}$ doping the edge position shifts towards the value

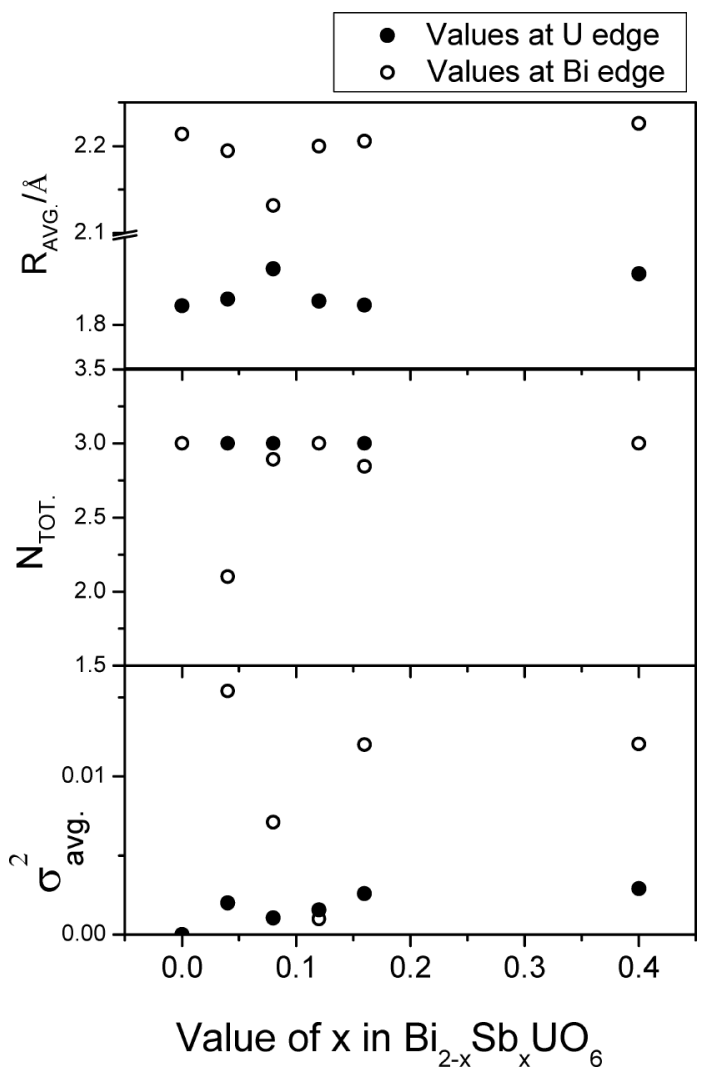

Fig. 5 Variation of the average bond length $\left(\mathrm{R}_{\mathrm{AVG}}\right)$, The total coordination number $\left(\mathrm{N}_{\text {Tот. }}\right)$ and average DW factor $\left(\sigma^{2}\right)$ for the two nearest oxygen shells surrounding $\mathrm{Bi}$ and $\mathrm{U}$ sites as a function of $\mathrm{x}$ for the products obtained while preparing $\mathrm{Bi}_{2-\mathrm{x}} \mathrm{Sb}_{\mathrm{x}} \mathrm{UO}_{6}$ samples. 
observed for the undoped sample. The results of EXAFS measurements on the samples also support this observation, since the bond length, coordination number and $\sigma^{2}$ values are found to vary significantly for the Sb doping concentration up to $4 \%(\mathrm{x}=0.08)$. No chemical shift was observed for the U edge positions of the samples with the incorporation of $\mathrm{Bi}$, indicating that $\mathrm{Sb}$ doping only affects the $\mathrm{Bi}$ sites and not the $\mathrm{U}$ sites.

\section{Acknowledgements}

The authors are thankful to Dr. S. K. Aggarwal, Associate Director (R), RC \& I Group, BARC, Dr. S. Kannan, Head X-ray and Structural Studies Section, FCD, BARC and Dr. N. K. Sahoo Head Spectroscopy Division, BARC for their keen interest in this work.

\section{References}

1. S. Dash and Z. Singh, J. Nucl. Mater., 2010, 404, 9.

2. L. Smith, P. E. Raison, and R. J. M. Konings, J. Nucl. Mater., 2011, 413, 114.

3. A. Nakamura, Y. Doi, and Y. Hinatsu, J. Solid State Chem., 2011, 184, 531.

4. N. L. Misra, D. Lahiri, K. D. S. Mudher, L. Olivi, and S. M. Sharma, X-Ray Spectrom., 2008, 37, 215.

5. A. V. Soldatov, D. Lamoen, M. J. Konstantinovic, S. Van den Berghe, A. C. Scheinost, and M. Verwerft, J. Solid State Chem., 2007, 180, 53.

6. D. White and S. Ramdas, Ultramicroscopy, 1989, 31, 124.

7. H. Collette, V. Deremince-Mathieu, Z. Gabelica, J. B. Nagy, E. G. Derouane, and J. J. Verbist, J. Chem. Soc. Faraday Trans. 2, 1987, 83, 1263.

8. I. V. Dulera and R. K. Sinha, J. Nucl. Mater., 2008, 383, 183.

9. A. S. Koster, J. P. P. Renaud, and G. D. Rieck, Acta Crystallogr., Sect. B: Struct. Sci., 1975, 31, 127.

10. N. Bonanos, Mater. Res. Bull., 1989, 24, 1531.

11. O. Thery, R. N. Vannier, C. Dion, and F. Abraham, Solid State Ionics, 1996, 90, 105.
12. D. O. Charkin, D. N. Lebedev, S. Y. Stefanovich, and S. M. Kazakov, Solid State Sci., 2010, 12, 2079.

13. R. N. Vannier, O. Théry, C. Kinowski, M. Huvé, G. Van Tendeloo, E. Suard, and F. Abraham, J. Mater. Chem., 1999, 9, 435.

14. J. Rodriguez-Carjaval, Proceedings of the Satellite Meeting on Powder Diffraction, Toulouse, 1990, 127.

15. A. K. Sinha, A. Sagdeo, P. Gupta, A. Kumar, M. N. Singh, R. K. Gupta, S. R. Kane, and S. K. Deb, AIP Conf. Proc., 2011, 1349, 503.

16. D. Bhattacharyya, A. K. Poswal, S. N. Jha, Sangeeta, and S. C. Sabharwal, Nucl. Instrum. Methods phys. Res., Sect. A, 2009, 609, 286.

17. Neetika, A. Das, I. Dhiman, A. K. Nigam, A. K. Yadav, D. Bhattacharyya, and S. S. Meena, J. Appl. Phys., 2012, 112, 123913

18. S. Basu, S. Varma, A. N. Shirsat, B. N. Wani, S. R. Bharadwaj, A. Chakrabarti, S. N. Jha, and D. Bhattacharyya, J. Appl. Phys., 2012, 111, 053532.

19. S. Basu, B. S. Naidu, M. Pandey, V. Sudarsan, S. N. Jha, D. Bhattacharyya, R. K. Vatsa, and R. J. Kshirsagar, Chem. Phys. Lett., 2012, 528, 21.

20. J. Mondal, A. Modak, A. Dutta, S. Basu, S. N. Jha, D. Bhattacharyya, and A. Bhaumik, Chem. Commun., 2012, 48, 8000 .

21. S. K. Pandey, A. R. Chetal, and P. R. Sarode, J. Phys. Soc. Jpn., 1990, 59, 1848.

22. H. K. Hinge, S. K. Joshi, B. D. Shrivastava, J. Prasad, and K. Srivastava, Indian J. Pure Appl. Phys., 2011, 49, 168.

23. D. Joseph, S. Basu, S. N. Jha, and D. Bhattacharyya, Nucl. Instrum. Methods Phys. Res., Sect. B, 2012, 274, 126.

24. A. R. Chetal, P. Mahto, and P. R. Sarode, J. Phys. Chem. Solids, 1988, 49, 279.

25. C. Mande and M.Y. Apte, Bull. Mater. Sci., 1981, 3, 193.

26. J. P. Suchet, "Chemical Physics of Semiconductors", 1965, Van Nostrand, London.

27. "X-Ray Absorption: Principles, Applications, Techniques of EXAFS, SEXAFS and XANES", ed. D. C. Konigsberger and R. Prince, 1988, Wiley, New York.

28. B. Ravel and M. Newville, J. Synchrotron Radiat., 2005, $12,537$. 